\title{
Prevalence and determinants of distress among oncology patients at a tertiary care medical city in Riyadh, Saudi Arabia
}

Luluh Y. Alsughayer, MBBS, Lamees A. Altamimi, MBBS, Futoon S. Alsaleh, MBBS, Lamya Alsaghan, MBBS,

Ibrahim Alfurayh, MD, Nashwa M. Abdel-Aziz, MD, Khalid A. Alsaleh, MBBS, FRCPC, Fahad D. Alosaimi, MD.

\begin{abstract}
الأهداف : تقدير مدى انتشار الكدر لدى مرضى السرطان في المملكة العربية

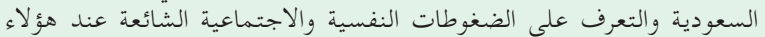

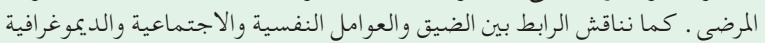
والطبية.

المنهجية : أجريت هذه الدراسة المقطعية في عيادة الأورام الخارجية في المدينة

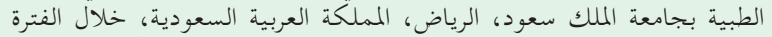

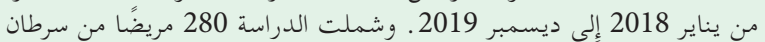

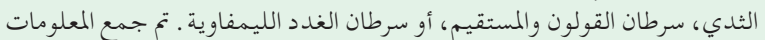

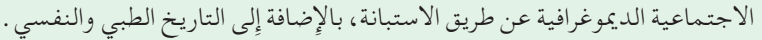

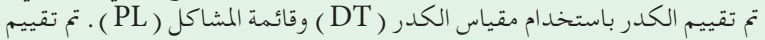

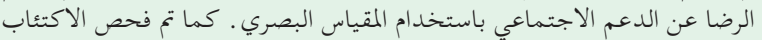

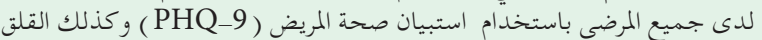

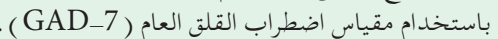

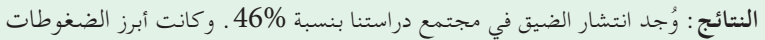

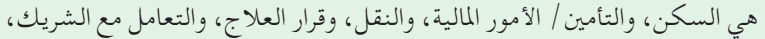

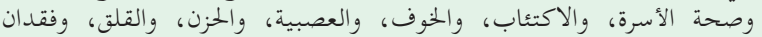

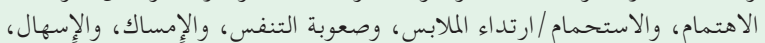

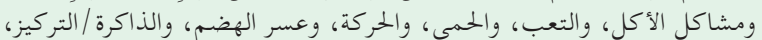

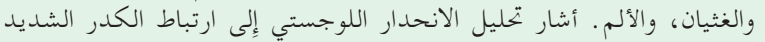

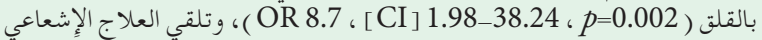

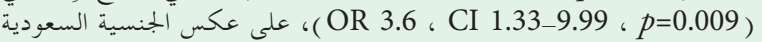

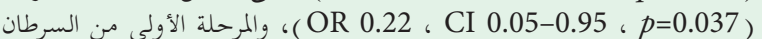
(OR 0.18 ، CI 0.05-1.40 ، بضيق أقل ، (OR=0.002)

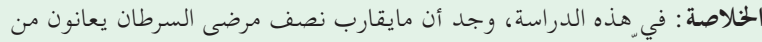

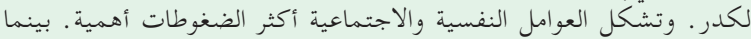

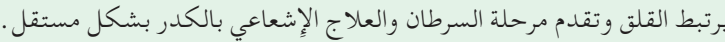

Objectives: To estimate the prevalence of distress in patients with cancer in Saudi Arabia and to identify common psychosocial stressors in these patients. We also looked for associations between distress and psychological, sociodemographic, and medical factors.

Methods: This cross-sectional study was performed in the oncology outpatient clinic at King Saud University Medical City, Riyadh, Saudi Arabia, from January 2018 to December 2019. It included 280 patients with breast cancer, colorectal cancer, or lymphoma.
Sociodemographic information was collected using questionnaire, along with information on medical history and any psychiatric history. Distress was assessed using the Distress Thermometer and Problem List. Satisfaction with social support was rated using the visual analog scale. All patients were screened for depression using the Patient Health Questionnaire 9-item depression scale and anxiety using the Generalized Anxiety Disorder 7-item scale.

Results: The prevalence of distress in our study population was found to be $46 \%$. Distress was associated with several practical, family, emotional, and physical stressors in the problem list. Logistic regression identified predictors of distress to be anxiety (odds ratio [OR] 8.7, confidence interval $[\mathrm{CI}]$ 1.98-38.24, $p=0.002)$ and receiving radiotherapy (OR 3.6, CI 1.33-9.99, $p=0.009$ ), while Saudi nationality (OR 0.22 , CI $0.05-0.95, p=0.037$ ) and stage I cancer (OR 0.18, CI 0.05-1.40, $p=0.002$ ) were associated with low distress.

Conclusion: Approximately half of cancer patients were found to have distress. Anxiety, advanced cancer stage, and radiotherapy were independently associated with distress.

Keywords: prevalence, distress, cancer, oncology, Saudi Arabia

Saudi Med J 2021; Vol. 42 (7): 761-768 doi: 10.15537/smj.2021.42.7.20210121

From the College of Medicine (Alsughayer, Altamimi, Alsaleh, Alsaghan); from the Psychiatry Department (Alfuraih, Alosaimi); HematologyOncology Center (Abdel-Aziz, Alsaleh), King Saud University, Riyadh, Kingdom of Saudi Arabia; and from the Department of Medical Oncology (Abdel-Aziz), South Egypt Cancer Institute, Assiut University, Assiut, Egypt.

Received 21st February 2021. Accepted 31st May 2021.

Address correspondence and reprint request to: Dr. Futoon S. Alsaleh, College of Medicine, King Saud University, Riyadh, Kingdom of Saudi Arabia.E-mail: Futoonsas@gmail.com

ORCID ID: https://orcid.org/0000-0002-3881-569X 
$\mathrm{O}$ ncology patients are particularly vulnerable to distress and a myriad of psychosocial morbidity. The revised guidelines published by the National Comprehensive Cancer Network (NCCN) in 2020 define distress as "a multifactorial unpleasant experience of a psychological (such as, cognitive, behavioral, emotional), social, spiritual, or physical nature that may interfere with one's ability to cope effectively with cancer, its physical symptoms, and its treatment. Distress extends along a continuum, ranging from common normal feelings of vulnerability, sadness, and fears to problems that can become disabling, such as depression, anxiety, panic, social isolation, and existential and spiritual crisis."

Distress is common in patients with cancer. One study reported that approximately $30 \%-43 \%$ of these patients experience some form of distress during their cancer journey. ${ }^{2}$ Nevertheless, it has been estimated that less than $30 \%$ of oncology patients with psychosocial issues are identified. ${ }^{3}$ Therefore, relatively few affected patients receive appropriate assessment and intervention. According to the International Agency for Research on Cancer, there were 82,640 oncology patients in Saudi Arabia in 5 years. ${ }^{4}$ However, little research attention has been paid to the prevalence of distress in this large group of patients. Recognizing the magnitude of the problem is important for development of patient support services and training of health care professionals. Therefore, this study aimed to identify the prevalence of distress in patients with cancer and the most common stressors in this group. We also explored the association between distress and psychological, sociodemographic, and medical factors with a view to improving early detection and implementing an intervention strategy.

Methods. This cross-sectional study was performed between January 2018 and December 2019 in the oncology outpatient clinic at King Saud University Medical City, Riyadh, Saudi Arabia. The study protocol was approved by the Institutional Review Board of the Faculty of Medicine at King Saud University (project E-17-2769). Trained data collectors and nurses screened patients for distress as they attended clinic

Disclosure. Authors have no conflict of interests, and the work was not supported or funded by any drug company. This study was supported by the Oncology Center, Thrombosis and Hemorrhagic Center, King Saud University Medical City, Riyadh, Kingdom of Saudi Arabia. appointments. Two hundred and eighty were enrolled in the study by convenience sampling.

Inclusion criteria involves patients with the most encountered types of cancer (breast cancer, colorectal cancer, and lymphoma), excluding those $<15$ years old. All patients signed an informed consent form.

Sociodemographic data were collected by questionnaire, along with information on medical history and any self-reported psychiatric history. Distress was evaluated using the distress thermometer (DT) and problem list (PL). Satisfaction with social support was scored on a $10-\mathrm{mm}$ visual analog scale (VAS). All patients were screened for depression using the Patient Health Questionnaire 9-item (PHQ-9) and for anxiety using the Generalized Anxiety Disorder 7-item (GAD-7).

The DT was created by the NCCN to screen for distress in oncology patients. This tool measures distress on 0 to 10 scale, with higher values indicating more distress. The DT also includes a PL designed to identify possible sources of distress in 5 areas (practical problems, family problems, emotional problems, spiritual or religious concerns, and physical problems). We used the validated Arabic version of the DT, with a cut-off value of $\geq 4$ indicating distress. ${ }^{5}$ The PHQ is widely used to screen for psychiatric disorders. The Arabic version of the PHQ was found to be valid and reliable in screening for many psychiatric disorders, including depression (PHQ-9) and anxiety (GAD-7). ${ }^{6}$ Both the PHQ-9 and GAD-7 are highly specific and sensitive for detection of depression and anxiety at a cut-off score $>10$. Cut off points of 5,10, and 15 represent mild, moderate, and severe anxiety on the GAD-7, similar to levels of depression on the PHQ-9.7,8 Patients' satisfaction with social support was assessed using the visual analogue scale (VAS). The VAS is a $10 \mathrm{~mm}$ line with anchor statements on the left (extremely dissatisfied) and on the right (very satisfied). The patient is asked to mark their level of satisfaction towards social support on the line, resembling a score of 0 to 10 . A VAS cut-off of 8 was estimated by the $75 \%$ quartile and considered 'satisfied'.

Continuous variables are reported as mean \pm standard deviation and categorical variables as proportion. The Student's t-test or Wilcoxon rank-sum test were used to evaluate continuous variables and the Chi-squared test or Fisher's exact to examine the categorical data. Significant variables $(p<0.05)$ in univariate analysis were included in a logistic regression model to identify predictors of severe distress. All tests were 2-sided and a $p$-value of $<0.05$ was considered statistically significant in the logistic regression model. The statistical analysis 
were performed using JMP Pro software version 14.0 (SAS Institute Inc., Cary, NC, USA).

Literature review was performed using the keywords including "distress" and "cancer" through Pubmed and Google Scholar. References of retrieved articles were then schemed for more publications relevant to our study.

Results. Of the 280 patients (103 male, 177 female) who agreed to participate in the study, 129 were distressed (scored $\geq 4$ on the DT). The prevalence of distress was found to be $46 \%$. The distribution of DT scores is shown in Figure 1.

Baseline characteristics and demographic data are provided in Table 1 . Distressed patients (DT score $\geq 4$ ) were predominantly female $(71 \%)$, had a mean age of $51.1 \pm 12.6$ years $p=0.009)$, and were more likely to be Saudi nationals $(p=0.001)$ and householders $(p=0.05)$. Distress was prevalent most in patients with breast cancer $(n=66,51 \%)$, followed by colon cancer $(n=45$, $35 \%)$, and lymphoma ( $\mathrm{n}=18,14 \%)$.

The relationship between distress and clinical and psychological characteristics is shown in Table 2 and Table 3. Statistically significant associations were found with type of cancer $(p=0.05)$, cancer stage $(p=0.003)$, psychiatric follow up $(17 \%, p<0.0001)$, psychiatric comorbidity $(13 \%, p<0.0001)$, use of psychiatric medication $(12 \%, p=0.0007)$, and receiving radiotherapy $(p=0.03)$. The mean depression score was $8.4 \pm 5.0,(p<0.0001) ; 43$ (33\%) of distressed patients had depression (score $>9)$, and $17(13 \%)$ had suicidal ideation $(p<0.001)$. The mean anxiety score was $7.8 \pm$ $5.8(p<0.0001) ; 48(37 \%)$ of distressed patients had anxiety (score $>9)$. The mean score for satisfaction with social support was $8.4 \pm 2.0,(p<0.0006)$, with only $73(57 \%)$ of the distressed patients being satisfied (score $>8$ ).

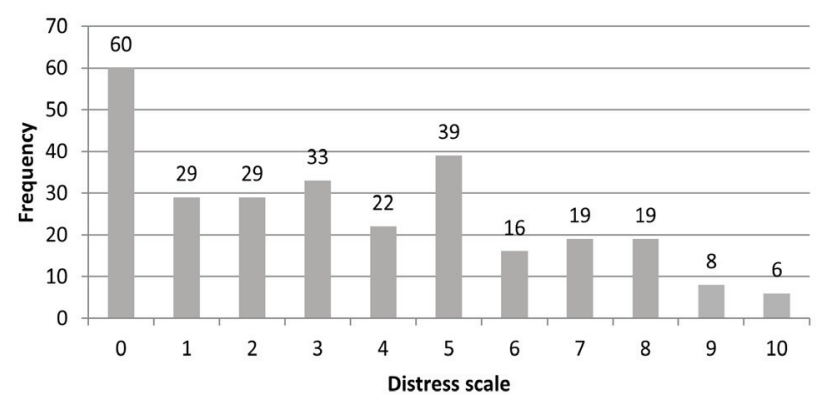

Figure 1 - Distribution of distress scores among cancer patients in Saudi Arabia $(\mathrm{N}=280)$
Table 1 - Baseline sociodemographic characteristics and DT score among cancer patients in Saudi Arabia $(\mathrm{N}=280)$.

\begin{tabular}{|c|c|c|c|c|}
\hline Variable & $\begin{array}{c}\text { DT score } \\
\geq 4, n=129\end{array}$ & $\begin{array}{l}\text { DT score } \\
<4, n=151\end{array}$ & Total & $P$-value \\
\hline \multicolumn{5}{|l|}{ Age (years) } \\
\hline Mean (SD) & $51.1(12.6)$ & $52.5(15.5)$ & $51.8(14.3)$ & 0.3 \\
\hline $15-42$ & $25(19)$ & $35(23)$ & $60(21)$ & \\
\hline $43-60$ & $74(57)$ & $67(44)$ & $141(50)$ & \\
\hline$>60$ & $30(23)$ & $49(33)$ & $79(28)$ & 0.08 \\
\hline \multicolumn{5}{|l|}{ Gender } \\
\hline Male & $37(29)$ & $66(44)$ & $103(37)$ & 0.009 \\
\hline Female & $92(71)$ & $85(56)$ & $177(63)$ & \\
\hline \multicolumn{5}{|l|}{ Nationality } \\
\hline Saudi & $99(7)$ & $137(91)$ & $236(84)$ & 0.001 \\
\hline Non-Saudi & $30(23)$ & $14(9)$ & $44(16)$ & \\
\hline \multicolumn{5}{|l|}{ Residence } \\
\hline Owned & $84(6)$ & $114(76)$ & $198(71)$ & 0.05 \\
\hline Rented & $45(44)$ & $37(24)$ & $82(29)$ & \\
\hline \multicolumn{5}{|l|}{ Employed } \\
\hline Yes & $32(25)$ & $45(30)$ & $77(27)$ & 0.3 \\
\hline No & $97(75)$ & $106(70)$ & $203(73)$ & \\
\hline \multicolumn{5}{|l|}{$\begin{array}{l}\text { Household } \\
\text { residents }\end{array}$} \\
\hline Mean (SD) & $6(2.7)$ & $6(2.8)$ & $6(2.7)$ & 0.9 \\
\hline$\leq 4$ & $39(30)$ & $42(28)$ & $81(29)$ & \\
\hline $4-8$ & $69(54)$ & $82(54)$ & $151(54)$ & 0.8 \\
\hline$>8$ & $21(16)$ & $27(18)$ & $48(17)$ & \\
\hline \multicolumn{5}{|l|}{ Marital status } \\
\hline Married & $106(82)$ & $121(80)$ & $227(81)$ & \\
\hline Single & $12(9)$ & $19(13)$ & $31(11)$ & 0.7 \\
\hline Divorced & $6(5)$ & $6(5)$ & $13(5)$ & \\
\hline Widow/widower & $5(4)$ & $5(4)$ & $9(3)$ & \\
\hline \multicolumn{5}{|l|}{ Income (SR) } \\
\hline$<5000$ & $51(40)$ & $61(40)$ & $112(40)$ & \\
\hline $5000-10,000$ & $30(23)$ & $32(21)$ & $62(22)$ & \\
\hline $10,001-15,000$ & $26(20)$ & $29(19)$ & $55(20)$ & 0.9 \\
\hline $15,001-20,000$ & $13(10)$ & $18(12)$ & $31(11)$ & \\
\hline$\geq 20,000$ & $9(7)$ & $11(7)$ & $20(7)$ & \\
\hline \multicolumn{5}{|l|}{ Education } \\
\hline $\begin{array}{l}\text { Below high } \\
\text { school }\end{array}$ & $48(37)$ & $50(33)$ & $98(35)$ & \\
\hline High school & $34(26)$ & $34(23)$ & $68(24)$ & \\
\hline Bachelor's degree & $41(32)$ & $57(38)$ & $98(35)$ & 0.1 \\
\hline Master's degree & $2(2)$ & $9(6)$ & $11(4)$ & \\
\hline $\mathrm{PhD}$ & $4(3)$ & $1(1)$ & $5(2)$ & \\
\hline \multicolumn{5}{|l|}{ Region of residence } \\
\hline Central & $108(84)$ & $116(77)$ & $224(80)$ & \\
\hline South & $6(5)$ & $13(9)$ & $19(7)$ & \\
\hline West & $8(6)$ & $8(6)$ & $15(5)$ & 0.1 \\
\hline North & $6(5)$ & $7(5)$ & $13(5)$ & \\
\hline East & $1(1)$ & $1(1)$ & $9(3)$ & \\
\hline
\end{tabular}

Values are presented as number and percentages (\%). DT: distress thermometer, SD: standard deviation, SR: Saudi Riyal, PhD: Doctor of Philosophy 
Table 2 - Clinical characteristics association with DT score among cancer patients in Saudi Arabia (N=280).

\begin{tabular}{lcccc}
\hline Variable & $\begin{array}{c}\mathrm{DT} \geq 4 \\
\mathbf{n}=\mathbf{1 2 9}\end{array}$ & $\begin{array}{c}\mathrm{DT}<4 \\
\mathrm{n}=\mathbf{1 5 1}\end{array}$ & $\begin{array}{c}\text { Total } \\
\mathrm{N}=\mathbf{2 8 0}\end{array}$ & $P$-value \\
\hline $\begin{array}{l}\text { Type of cancer } \\
\text { Breast }\end{array}$ & $66(51)$ & $56(37)$ & $122(44)$ & \\
Colon & $45(35)$ & $66(44)$ & $111(40)$ & 0.05 \\
Lymphoma & $18(14)$ & $29(19)$ & $47(16)$ & \\
Cancer stage & & & & \\
Undetermined & $62(48)$ & $83(55)$ & $145(52)$ & \\
1 & $4(3)$ & $20(13)$ & $24(9)$ & \\
2 & $26(20)$ & $20(13)$ & $46(16)$ & \\
3 & $20(16)$ & $17(11)$ & $37(13)$ & 0.003 \\
4 & $17(13)$ & $11(7)$ & $28(10)$ & \\
Treatment modality & $113(88)$ & $126(83)$ & $239(85)$ & 0.3 \\
Chemotherapy & $67(52)$ & $79(52)$ & $146(52)$ & 0.9 \\
Surgery & $47(36)$ & $37(25)$ & $84(30)$ & 0.03 \\
Radiotherapy & $19(15)$ & $14(9)$ & $33(12)$ & 0.1 \\
Hormonal therapy & $14(11)$ & $20(13)$ & $34(12)$ & 0.5 \\
Biological therapy & \multicolumn{4}{c}{ Values are presented as number and percentages (\%). DT: distress } \\
\multicolumn{4}{r}{ thermometer }
\end{tabular}

The results for the DT and PL are shown in Table 4. The most important stressors were housing $(p=0.0176)$, insurance/financial issues $(p=0.0086)$, transport problems $(p=0.0286)$, decisions regarding treatment $(p<0.0001)$, relationship with partner ( $p=0.0202)$, family health issues $(p=0.0412)$, depression $(p<0.0001)$, fear $(p<0.0001)$, nervousness $(p=0.0022)$, sadness $(p<0.0001)$, worry $(p=0.0005)$, loss of interest $(\mathrm{p}=0.0003)$, bathing/dressing problems $(p=0.0004)$, breathing difficulty $(p=0.004)$, constipation $(p=0.002)$, diarrhea $(p=0.02)$, eating $(p<0.0001)$, fatigue $(p=0.01)$, fever $(p=0.02)$, mobility problems $(p=0.012)$, indigestion $(p=0.0002)$, memory/concentration issues $(p=0.0006)$, nausea $(p=0.04)$, and pain $(p<0.0001)$.

The results of logistic regression analysis of variables that were statistically significant $(p<0.05)$ in univariate analysis is shown in Table 5. Predictors of severe distress were anxiety (odds ratio [OR] 8.7, confidence interval [CI] 1.98-38.24, $p=0.002$ ), receiving radiotherapy (OR 3.6, CI 1.33-9.99, $p=0.009$ ), while Saudi nationality (OR 0.22, CI $0.05-0.95, p=0.037$ ), and stage I cancer (OR 0.18, CI 0.05-1.40, $p=0.002$ ) were associated with less distress.

Discussion. This study found distress in approximately $46 \%$ of patients with cancer. Moreover, a significant proportion of these patients had psychiatric symptoms, including anxiety (37\%), depression (33\%), and suicidal ideation (13\%). However, the majority $(83 \%)$ of these patients had not seen a psychiatrist.
Table 3 - Association of psychological characteristics with DT score among cancer patients in Saudi Arabia ( $\mathrm{N}=280)$.

\begin{tabular}{|c|c|c|c|c|}
\hline Variable & $\begin{array}{l}\mathrm{DT} \geq 4 \\
\mathrm{n}=129\end{array}$ & $\begin{array}{l}\mathrm{DT}<4 \\
\mathrm{n}=151\end{array}$ & $\begin{array}{c}\text { Total } \\
\mathrm{N}=280\end{array}$ & $P$-value \\
\hline \multicolumn{5}{|l|}{ Visited a psychiatrist } \\
\hline Yes & $22(17)$ & $3(2)$ & $25(9)$ & \multirow[t]{2}{*}{$<0.0001$} \\
\hline No & $107(83)$ & $148(98)$ & $255(91)$ & \\
\hline \multicolumn{5}{|l|}{$\begin{array}{l}\text { Diagnosed with a } \\
\text { psychiatric illness }\end{array}$} \\
\hline Yes & $17(13)$ & $2(1)$ & $19(7)$ & \\
\hline Depression & $10(59)$ & $2(0)$ & $12(63)$ & \\
\hline $\begin{array}{l}\text { Adjustment } \\
\text { disorder }\end{array}$ & $2(12)$ & $0(0)$ & $2(11)$ & \\
\hline Stress disorder & $1(1)$ & $0(0)$ & $1(5)$ & \multirow{3}{*}{$<0.0001$} \\
\hline Anxiety & $1(1)$ & $0(0)$ & $1(5)$ & \\
\hline Did not answer & $3(18)$ & $0(0)$ & $3(16)$ & \\
\hline No & $112(87)$ & $149(99)$ & $261(93)$ & \\
\hline \multicolumn{5}{|l|}{$\begin{array}{l}\text { Using psychiatric } \\
\text { medication }\end{array}$} \\
\hline Yes & $15(12)$ & $3(2)$ & $18(6)$ & \multirow{2}{*}{0.0007} \\
\hline No & $114(88)$ & $148(98)$ & $262(94)$ & \\
\hline \multicolumn{5}{|l|}{ Depression (PHQ-9) } \\
\hline Mean score (SD) & $8.4(5)$ & $3.8(3.6)$ & $5.9(4.9)$ & $<0.0001$ \\
\hline Normal (score 0-9) & $86(67)$ & $139(92)$ & $225(80)$ & \multirow[t]{2}{*}{$<0.0001$} \\
\hline $\begin{array}{l}\text { Depression (score } \\
>9 \text { ) }\end{array}$ & $43(33)$ & $12(8)$ & $55(20)$ & \\
\hline \multicolumn{5}{|l|}{ Degree of depression } \\
\hline Minimal & $25(19)$ & $98(65)$ & $123(44)$ & \multirow{5}{*}{$<0.0001$} \\
\hline Mild & $61(47)$ & $41(27)$ & $102(36)$ & \\
\hline Moderate & $23(18)$ & $10(7)$ & $33(12)$ & \\
\hline Moderately severe & $15(12)$ & $2(1)$ & $17(6)$ & \\
\hline Severe & $5(4)$ & $0(0)$ & $5(2)$ & \\
\hline \multicolumn{5}{|c|}{ Individual PHQ-9 items } \\
\hline Loss of interest & $102(59.3)$ & $70(40.7)$ & $172(61.43)$ & $<0.001$ \\
\hline $\begin{array}{l}\text { Feeling 'down' or } \\
\text { depressed }\end{array}$ & $34(25.56)$ & $99(74.4)$ & $133(47.5)$ & $<0.001$ \\
\hline Suicidal ideation & $17(13)$ & $5(3)$ & $22(8)$ & 0.001 \\
\hline \multicolumn{5}{|l|}{ Anxiety (GAD-7) } \\
\hline Mean (SD) & $7.8(5.8)$ & $3.1(3.6)$ & $5.3(5.3)$ & $<0.0001$ \\
\hline Normal (score 0-9) & $81(63)$ & $138(91)$ & $61(22)$ & \multirow[t]{2}{*}{$<0.0001$} \\
\hline Anxiety (score >9) & $48(37)$ & $13(9)$ & $219(78)$ & \\
\hline \multicolumn{5}{|l|}{ Degree of anxiety } \\
\hline Minimal anxiety & $42(32)$ & $110(73)$ & $152(54)$ & \multirow[t]{4}{*}{$<0.0001$} \\
\hline Mild anxiety & $39(30)$ & $28(18)$ & $67(24)$ & \\
\hline Moderate anxiety & $28(22)$ & $12(8)$ & $40(14)$ & \\
\hline Severe anxiety & $20(16)$ & $1(1)$ & $21(8)$ & \\
\hline \multicolumn{5}{|l|}{$\begin{array}{l}\text { Satisfaction with social } \\
\text { support }\end{array}$} \\
\hline Mean (SD) & $8.4(2)$ & $9(1.2)$ & $8.8(1.7)$ & \multirow[t]{2}{*}{0.0006} \\
\hline Score $>8$ & $73(57)$ & $110(73)$ & $203(72)$ & \\
\hline Score $\leq 8$ & $56(43)$ & $41(27)$ & $77(28)$ & 0.004 \\
\hline $\begin{array}{l}\text { Values are present } \\
\text { thermometer, GAD-7 } \\
\text { 9: Patient Health Q }\end{array}$ & $\begin{array}{l}\text { as numbers } \\
\text { Generalized } A\end{array}$ & and percent & $\begin{array}{l}\text { ages (\%). DT } \\
\text { rder 7-item sc } \\
\text { SD: standard d }\end{array}$ & $\begin{array}{l}\text { distress } \\
\text { ale, PHQ- } \\
\text { eviation }\end{array}$ \\
\hline
\end{tabular}


Distress in oncology patients ... Alsughayer et al

Table 4 - Association of problem list scores with the DT score among cancer patients in Saudi Arabia (N=280).

\begin{tabular}{|c|c|c|c|c|}
\hline Variable & $\begin{array}{l}\mathrm{DT} \geq 4 \\
\mathrm{n}=129\end{array}$ & $\begin{array}{l}\text { DT }<4 \\
n=151\end{array}$ & $\begin{array}{c}\text { Total } \\
\mathrm{N}=280\end{array}$ & $P$-value \\
\hline \multicolumn{5}{|l|}{ Practical problems } \\
\hline Childcare & $7(50.0)$ & $7(50.0)$ & $14(5.0)$ & 0.7626 \\
\hline Housing & $16(69.6)$ & $7(30.4)$ & $23(8.2)$ & $0.0176^{*}$ \\
\hline Insurance/financial & $20(69.0)$ & $9(31.0)$ & $29(10.4)$ & $0.0086^{*}$ \\
\hline Transportation & $20(64.5)$ & $11(35.5)$ & $31(11.1)$ & $0.0286^{*}$ \\
\hline Work/School & $6(60.0)$ & $4(40.0)$ & $10(3.6)$ & 0.3686 \\
\hline Treatment decisions & $33(80.5)$ & $8(19.5)$ & $41(14.6)$ & $<0.0001^{*}$ \\
\hline \multicolumn{5}{|l|}{ Family problems } \\
\hline Dealing with children & $9(64.3)$ & $5(35.7)$ & $14(5.0)$ & 0.16 \\
\hline Dealing with partner & $13(72.2)$ & $5(27.8)$ & $18(6.4)$ & $0.0202^{*}$ \\
\hline Ability to have children & $4(66.7)$ & $2(33.3)$ & $6(2.1)$ & 0.3046 \\
\hline Family health issues & $18(64.3)$ & $10(35.7)$ & $28(10.0)$ & $0.0412^{*}$ \\
\hline \multicolumn{5}{|l|}{ Emotional problems } \\
\hline Depression & $23(88.5)$ & $3(11.5)$ & $26(9.3)$ & $<0.0001^{*}$ \\
\hline Fears & $54(66.7)$ & $27(33.3)$ & $81(28.9)$ & $<0.0001^{*}$ \\
\hline Nervousness & $93(41.5)$ & $131(58.5)$ & $224(80.0)$ & $0.0022^{*}$ \\
\hline Sadness & $36(85.7)$ & $6(14.3)$ & $42(15.0)$ & $<0.0001^{*}$ \\
\hline Worry & $40(65.6)$ & $21(34.4)$ & $61(21.8)$ & $0.0005^{*}$ \\
\hline Loss of interest in usual activities & $94(41.1)$ & $135(58.0)$ & $229(81.8)$ & $0.0003^{*}$ \\
\hline Spiritual/religious concerns & $7(5.0)$ & $3(2.0)$ & $10(4.0)$ & 0.1 \\
\hline \multicolumn{5}{|l|}{ Physical problems } \\
\hline Appearance & $24(19.0)$ & $18(12.0)$ & $42(15.0)$ & 0.1 \\
\hline Bathing/dressing & $16(12.0)$ & $3(2.0)$ & $19(7.0)$ & $0.0004^{*}$ \\
\hline Breathing & $30(23.0)$ & $16(11.0)$ & $46(16.0)$ & $0.004^{*}$ \\
\hline Changes in urination & $21(16.0)$ & $16(11.0)$ & $37(13.0)$ & 0.1 \\
\hline Constipation & $42(33.0)$ & $26(17.0)$ & $68(24.0)$ & $0.002^{*}$ \\
\hline Diarrhea & $34(26.0)$ & $23(15.0)$ & $57(20.0)$ & $0.02^{*}$ \\
\hline Eating & $31(24.0)$ & $11(7.0)$ & $42(15.0)$ & $<0.0001^{*}$ \\
\hline Fatigue & $63(49.0)$ & $53(35.0)$ & $116(41.0)$ & $0.01^{*}$ \\
\hline Feeling swollen & $23(18.0)$ & $17(11.0)$ & $40(14.0)$ & 0.1 \\
\hline Fevers & $15(12.0)$ & $7(5.0)$ & $22(8.0)$ & $0.02^{*}$ \\
\hline Getting around & $30(23.0)$ & $18(12.0)$ & $48(17.0)$ & $0.012^{*}$ \\
\hline Indigestion & $19(15.0)$ & $4(3.0)$ & $23(8.0)$ & $0.0002^{*}$ \\
\hline Memory/concentration & $29(22.0)$ & $12(8.0)$ & $41(15.0)$ & $0.0006^{*}$ \\
\hline Mouth sores & $20(16.0)$ & $15(10.0)$ & $35(13.0)$ & 0.1 \\
\hline Nausea & $38(29.0)$ & $29(19.0)$ & $67(24.0)$ & $0.04^{*}$ \\
\hline Nose dry/congested & $22(17.0)$ & $21(14.0)$ & $43(15.0)$ & 0.4 \\
\hline Pain & $41(32.0)$ & $15(10.0)$ & $56(20.0)$ & $<0.0001^{*}$ \\
\hline Sexual & $3(2.0)$ & $1(1.0)$ & $4(1.0)$ & 0.2 \\
\hline Skin dry/itchy & $39(30.0)$ & $31(21.0)$ & $70(25.0)$ & 0.06 \\
\hline Substance abuse & $0(0)$ & $1(1.0)$ & $1(0.4 .0)$ & 0.2 \\
\hline Tingling in hands/feet & $53(41.0)$ & $48(32.0)$ & $101(36.0)$ & 0.1 \\
\hline
\end{tabular}

Values are presented as numbers and percentages (\%). *statistically significant with a p-value of $\mathrm{p}<0.05$. DT: distress thermometer. 
Table 5 - Logistic regression analysis of potential risk factors for severe distress (DT score $\geq 4$ ) among cancer patients in Saudi Arabia $(\mathrm{N}=280)$.

\begin{tabular}{lcc}
\hline Variable & OR $(95 \%$ CI $)$ & $P$-value \\
\hline Male gender & $0.6(0.2-1.79)$ & 0.356 \\
Saudi nationality & $0.22(0.05-0.95)$ & 0.037 \\
Householders & $1.35(0.43-4.21)$ & 0.6 \\
Type of cancer (breast) & $0.42(0.13-1.4)$ & 0.155 \\
Cancer stage (=1) & $0.18(0.05-1.4)$ & 0.002 \\
Radiotherapy & $3.6(1.33-9.99)$ & 0.009 \\
Anxiety (GAD-7 score >9) & $8.7(1.98-38.24)$ & 0.002 \\
Depression (PHQ-9 score $>9)$ & $3.64(0.83-15.94)$ & 0.076 \\
Satisfaction with social support & $0.64(0.23-1.78)$ & 0.391 \\
\hline \multicolumn{2}{c}{ CI: confidence interval, DT: distress thermometer, OR: odds ratio, } \\
GAD-7: Generalized Anxiety Disorder 7-item scale, PHQ-9: Patient \\
\multicolumn{2}{c}{ Health Questionnaire 9-item scale } \\
\hline
\end{tabular}

Researchers in the United States have estimated that $22.8 \%-66.3 \%$ of patients with cancer experience distress. ${ }^{9,10}$ This wide range of estimates may reflect differences in the assessment tools and methodologies used in the studies. Several tools have been used to screen for distress in patients with cancer, including the Psychological Distress Inventory, Psychological Distress Scale, Questionnaire on Distress in Cancer PatientsShort Form, Screening Inventory for Psychosocial Problems, visual analog scale, the Brief Symptom Inventory, General Health Questionnaire, and the DT. ${ }^{11}$

In our study, we used the DT, which is a highly specific and sensitive screening instrument for distress validated in Arabic. The Arabic DT with a cutoff score of 4 correctly identified distress in $62 \%$ of cancer patients in Saudi Arabia. ${ }^{5}$

Distress has a significant impact on patients' quality of life and satisfaction with care. Moderate to severely distressed patients have significantly lower quality of life (QoL) than those with expected or mild levels of distress. The DT is a rapid screening tool that is easy to use and alerts the health care team to clinically relevant alterations in a patient's QoL. ${ }^{12}$ Blenkiron et $\mathrm{al}^{13}$ show qualitative analysis of feedback following psychooncology input suggested that patients particularly value generic therapeutic skills (such as supportive listening) provided by a professional who is not involved in their physical care.

We did not find an association of demographic characteristics or socioeconomic status with distress, except for Saudi nationality, which could be linked to social support. Herschbach et $\mathrm{al}^{14}$ were similarly unable to identify any general risk factors for distress in patients with cancer, which they attributed to variation in the relevant demographic and medical characteristics between the diagnostic subgroups. However, other studies have identified several predictors of severe distress in patients with cancer, including younger age, practical and emotional problems, ${ }^{10}$ female gender, lack of education, low performance status, ${ }^{15}$ head and neck cancer, and not receiving chemotherapy. ${ }^{16}$ The prevalence of distress is reportedly higher in patients with breast cancer $(40.9 \%)$ than in those with other types of cancer. ${ }^{14}$ In our study, radiotherapy was the only treatment modality that was significantly associated with distress. This finding is in line with a study performed in an outpatient radiotherapy clinic that found the rates of anxiety (15\%), depression (5.7\%), and overall psychological distress (22\%). ${ }^{17}$ Furthermore, a non-blinded, 2-arm, parallel-group, randomized controlled study performed at 2 centers found high levels of distress, including physical (84\%) and emotional $(56 \%)$ problems, in patients starting radiotherapy or chemotherapy. ${ }^{18}$

Other psychological characteristics can affect patients with cancer and predispose them to distress. Anxiety $(60.5 \%)$ and depression (50.8\%) have been commonly documented in oncology patients in Saudi Arabia. ${ }^{19}$ Contributory factors were found to be: education level, family history of cancer, severity of pain, and patients' awareness of their psychological issues. ${ }^{20}$ However, distress was positively correlated with anxiety scores, but not with depression scores. ${ }^{21}$

The benefit of screening for distress in the oncology setting remains controversial. In line with previous studies, our results support the need for evaluation and management of distress in patients with cancer. One study found that $47 \%$ of patients with significant distress were not identified prior to screening and did not receive appropriate supportive care. ${ }^{2}$ The DT has been reported to be effective for detecting distress and increasing the referral rate to psycho-oncological counselling.,22 A systematic review also provided evidence to support upgrading the DT from a screening instrument to an active facilitator of distress management care program. ${ }^{23}$ Moreover, the DT was found to be an efficient and valid single-item measure that was sensitive enough to identify changes in distress in callers ringing a cancer-specific helpline. ${ }^{24}$ However, other reviewers have cast doubt on the efficacy of implementing distress screening in oncology patients, provided that their distress typically improves only on referral to support services. ${ }^{25,26}$ Meanwhile, the high demand outweighs the potentials of psychosocial services. ${ }^{27}$ Although clinicians have conflicting views regarding implementation of routine 
distress screening, ${ }^{28}$ a review that includes 30 papers ${ }^{29}$ found that a large number of patients were willing to be assessed at all visits. Other researchers reported that $78 \%$ of patients with cancer were interested in talking to a social worker or behavioral health specialist and that $69 \%$ were interested in being part of a support group, ${ }^{30}$ which suggests that patients need more than screening alone. Indeed, researchers in the United Kingdom found a significant reduction in distress following a period of psycho-oncology care, including a significant decrease in emotional problems of 15\%-24\% despite no significant change in physical health or practical problems. ${ }^{13}$

Therefore, based on the current literature, we recommend routine distress screening for oncology patients and further evaluation and psychiatric referral of those found to be distressed. We also recommend a multidisciplinary screening and management approach that involves the oncologist, psychiatrist, nurse, social worker, family, and a patient support advocate.

Study limitations. A relatively small sample size, convenient sampling from one center, sampling bias towards breast, colorectal cancer, and lymphoma, which should be borne in mind when interpreting its findings. Longitudinal multicenter studies with larger sample sizes are needed to establish the optimal timing for screening, diagnosis, and follow-up and to further evaluate the impact of screening on patient outcomes.

In conclusion, $46 \%$ of patients with cancer were found to have distress. Anxiety, advanced cancer stage, and radiotherapy were independently associated with distress. Future studies should highlight the importance of psychosocial care as a pivotal component in the management of oncology patients. A multidisciplinary approach that includes early detection, intervention, and patient counseling is needed to minimize patients' distress and increase their overall satisfaction with care and quality of life.

Acknowledgment. The authors acknowledge Essam Almasri, Minyal Bawazier, Rawan Alqahtani, and Waad Alhuqbani for their significant contribution to collection of the study data. We acknowledge the support we received from the Oncology Center, Thrombosis and Hemorrhagic Center, King Saud University Medical City, Riyadh, Kingdom of Saudi Arabia. We would like to thank Susan Albrecht, MedSurgBio Ltd, for English language editing.

\section{References}

1. Riba MB, Donovan KA, Andersen B, Braun I, Breitbart WS, Brewer BW, et al. Distress management, version 3.2019, NCCN Clinical Practice Guidelines in Oncology. J Natl Compr Canc Netw 2019; 17: 1229-1249.
2. Zabora J, BrintzenhofeSzoc K, Curbow B, Hooker C, Piantadosi S. The prevalence of psychological distress by cancer site. Psychooncology 2001; 10:19-28.

3. Fallowfield L, Ratcliffe D, Jenkins V, Saul J. Psychiatric morbidity and its recognition by doctors in patients with cancer. Br J Cancer 2001; 84: 1011-1015.

4. World Health Organization. The International Agency for Research on Cancer (IARC). Global Cancer Statistics 2020. Population Fact Sheets (Saudi Arabia). [Updated 2021 March. Accessed on 2021 February 2]. Available from: https://gco.iarc. $\mathrm{fr} /$ today/fact-sheets-populations

5. Alosaimi FD, Abdel-Aziz N, Alsaleh K, AlSheikh R, AlSheikh R, Abdel-Warith A. Validity and feasibility of the Arabic version of distress thermometer for Saudi cancer patients. PLoS One 2018; 13: e0207364.

6. AlHadi AN, AlAteeq DA, Al-Sharif E, Bawazeer HM, Alanazi $\mathrm{H}$, AlShomrani AT, et al. An Arabic translation, reliability, and validation of patient health questionnaire in a Saudi sample. Ann Gen Psychiatry 2017; 16: 32.

7. Spitzer RL, Kroenke K, Williams JB, Löwe B. A brief measure for assessing generalized anxiety disorder: the GAD-7. Arch Intern Med 2006; 166: 1092-1097.

8. Kroenke K, Spitzer RL, Williams JB. The PHQ-9: validity of a brief depression severity measure. J Gen Intern Med 2001; 16: 606-613.

9. VanHoose L, Black LL, Doty K, Sabata D, Twumasi-Ankrah P, Taylor S, et al. An analysis of the distress thermometer problem list and distress in patients with cancer. Support Care Cancer 2015; 23: 1225-1232.

10. Acquati C, Kayser K. Predictors of psychological distress among cancer patients receiving care at a safety-net institution: the role of younger age and psychosocial problems. Support Care Cancer 2017; 25: 2305-2312.

11. Carlson LE, Waller A, Mitchell AJ. Screening for distress and unmet needs in patients with cancer: review and recommendations. J Clin Oncol 2012; 30: 1160-1177.

12. Head BA, Schapmire TJ, Keeney CE, Deck SM, Studts JL, Hermann CP, et al. Use of the distress thermometer to discern clinically relevant quality of life differences in women with breast cancer. Qual Life Res 2012; 21: 215-223.

13. Blenkiron P, Brooks A, Dearden R, McVey J. Use of the distress thermometer to evaluate symptoms, outcome and satisfaction in a specialist psycho-oncology service. Gen Hosp Psychiatry 2014; 36: 607-612.

14. Herschbach P, Keller M, Knight L, Brandl T, Huber B, Henrich $G$, et al. Psychological problems of cancer patients: a cancer distress screening with a cancer-specific questionnaire. $\mathrm{Br} J$ Cancer 2004; 91: 504-511.

15. Kim SJ, Rha SY, Song SK, Namkoong K, Chung HC, Yoon $\mathrm{SH}$, et al. Prevalence and associated factors of psychological distress among Korean cancer patients. Gen Hosp Psychiatry 2011; 33: 246-252.

16. Chiou YJ, Chiu NM, Wang LJ, Li SH, Lee CY, Wu MK, et al. Prevalence and related factors of psychological distress among cancer inpatients using routine distress thermometer and Chinese health questionnaire screening. Neuropsychiatr Dis Treat 2016; 12: 2765-2773.

17. Mackenzie LJ, Carey ML, Sanson-Fisher RW, D'Este CA. Psychological distress in cancer patients undergoing radiation therapy treatment. Support Care Cancer 2013; 21: 1043-1051.

18. Hollingworth W, Metcalfe C, Mancero S, Harris S, Campbell $\mathrm{R}$, Biddle $\mathrm{L}$, et al. Are needs assessments cost effective in reducing distress among patients with cancer? A randomized controlled trial using the distress thermometer and problem list. J Clin Oncol 2013; 31: 3631-3638. 
19. Al-Shahri MZ, Eldali AM, Al-Zahrani O. Nonpain symptoms of new and follow-up cancer patients attending a palliative care outpatient clinic in Saudi Arabia. Indian J Palliat Carev 2012;18: 98-102.

20. Khalil A, Faheem M, Fahim A, Innocent H, Mansoor Z, Rizvi $S$, et al. Prevalence of depression and anxiety amongst cancer patients in a hospital setting: a cross-sectional study. Psychiatry J 2016; 2016: 3964806.

21. Ng CG, Mohamed S, Kaur K, Sulaiman AH, Zainal NZ, Taib NA; MyBCC Study group. Perceived distress and its association with depression and anxiety in breast cancer patients. PLoS One 2017; 12: e0172975.

22. Götz A, Kröner A, Staudacher D, Spirig R: [Introduction of the stress thermometer in an oncology ward]. Pflege 2017; 30: 289-297.

23. Snowden A, White CA, Christie Z, Murray E, McGowan C, Scott R. The clinical utility of the distress thermometer: a review. Br J Nurs 2011; 20: 220-227.

24. Linehan K, Fennell KM, Hughes DL, Wilson CJ. Use of the Distress Thermometer in a cancer helpline context: can it detect changes in distress, is it acceptable to nurses and callers, and do high scores lead to internal referrals? Eur J Oncol Nurs 2017; 26: 49-55.
25. Meijer A, Roseman M, Delisle VC, Milette K, Levis B, Syamchandra A, et al. Effects of screening for psychological distress on patient outcomes in cancer: a systematic review. $J$ Psychosom Res 2013; 75: 1-17.

26. Coyne JC. Second thoughts about implementing routine screening of cancer patients for distress. Psycho-oncol 2013; 7 : 243-249.

27. Kendall J, Glaze K, Oakland S, Hansen J, Parry C. What do 1281 distress screeners tell us about cancer patients in a community cancer center? Psychooncology 2011; 20: 594-600.

28. Mitchell AJ, Lord K, Slattery J, Grainger L, Symonds P. How feasible is implementation of distress screening by cancer clinicians in routine clinical care? Cancer 2012; 118: 6260-6269.

29. Howell D, Molloy S, Wilkinson K, Green E, Orchard K, Wang $\mathrm{K}$, et al. Patient-reported outcomes in routine cancer clinical practice: a scoping review of use, impact on health outcomes, and implementation factors. Ann Oncol 2015; 26: 1846-1858.

30. Almigbal TH, Almutairi KM, Fu JB, Vinluan JM, Alhelih E, Alonazi WB, et al. Assessment of psychological distress among cancer patients undergoing radiotherapy in Saudi Arabia. Psychol Res Behav Manag 2019; 12: 691-700. 